\title{
Strategi Promosi Wisata Kota Bukittinggi Melalui Kuliner Nasi Kapau
}

Indonesian Journal of Tourism and Leisure, 2021
Vol. 02 (2),107-116
(C) The Journal, 2021
DOI: $10.36256 /$ ijtl.v2i2.163
https: / /journal.lasigo.org/index.php/IJTL
Article History
Received: Augustus $7^{\text {th }}, 2021$
Revised: October $20^{\text {th }}, 2021$
Accepted: October $25^{\text {th }}, 2021$

\section{Pepy Afrilian}

Jurusan Pariwisata Syariah, IAIN Batusangkar, Indonesia pepyafrilian@iainbatusangkar.ac.id

\section{Harry Yulianda}

Jurusan Pariwisata Syariah, IAIN Batusangkar, Indonesia harryyulianda@iainbatusangkar.ac.id

\section{Atika Afriani}

Jurusan Pariwisata Syariah, IAIN Batusangkar, Indonesia atikaafriani04@gmail.com

\begin{abstract}
Culinary has become its attraction that captivates the hearts of tourists. This is realized by the Bukittinggi City Government which will develop its tourist attraction through the culinary tourism potential of Nasi Kapau. Culinary Tourism started from additional facilities in the distribution of tourist activities but now the position of Nasi Kapau has turned into a tourist attraction that can be side by side with other attractions. To find out the position of Nasi Kapau to be used as a tourist promotion tool of Bukittinggi City, it needs to be started with an analysis of strengths, opportunities, weaknesses, and threats internally and externally, research seeks information by interviews by all Nasi swords that sell in bukittinggi slope market and spread angket to tourists who eat Nasi Kapau in bukittinggi slope market. The data obtained is analyzed descriptively about the marketing mix and the next data from the questionnaire is given weight and entered in the SWOT matrix so that it can answer the appropriate strategy for the promotion of Bukittinggi City through Nasi Kapau culinary tour. The results obtained are strategies that are suitable for the promotion of the city of Bukittinggi through Nasi Kapau Culinary tour is an aggressive strategy. Continuous promotion can also be done by mouth-to-mouth method or make Nasi Kapau as a talking point so as to attract other tourists to visit Bukittinggi out of curiosity about the taste of Nasi Kapau. In addition, Nasi Kapau costomers has been classified as a royal costomers so that it can dream up its review with pleasure.
\end{abstract}

Keywords: Tourism; Traditional Cuisine; Culinary Tourism; Marketing Mix

\author{
ABSTRAK

Kuliner sudah menjadi daya tarik sendiri yang memikat hati wisatawan. Hal tersebut disadari oleh Pemerintah Kota Bukittinggi yang akan mengembangkan daya tarik wisata nya melalui potensi wisata kuliner Nasi Kapau. Wisata Kuliner berawal dari fasilitas tambahan dalam penyelenggraan kegiatan wisata namun kini posisi Nasi Kapau sudah berubah menjadi daya tarik 
wisata yang dapat bersanding dengan objek wisata lainnya. Untuk mengetahui kedudukan Nasi Kapau untuk dijadikan tools atau alat promosi wisata Kota Bukittinggi maka perlu diawali dengan analisis kekuatan, peluang, kelemahan dan ancaman secara internal dan eksternal maka penelitian mencari informasi dengan wawancara oleh seluruh pedangan nasi kapau yang berjualan di pasar lereng Bukittinggi dan menyebarkan angket kepada wisatawan yang makan nasi kapau di pasar lereng Bukittinggi. Data yang didapatkan dianalisis dengan deskriptif mengenai marketing mix dan data selanjutnya dari angket tersebut diberi bobot dan masukkan dalam matriks SWOT sehingga dapat menjawab stertegi yang cocok untuk promosi Kota Bukittinggi melalui wisata kuliner Nasi Kapau. Adapun hasil yang didapatkan adalah strategi yang cocok digunakan untuk promosi kota Bukittinggi melalui wisata Kuliner Nasi Kapau adalah strategi yang agresif atau promosi dengan gencar. Promosi yang terus menerus juga dapat dilakukan dengan metode mulut ke mulut atau menjadikan Nasi Kapau sebagai bahan pembicaraan sehingga menarik wisatawan lain untuk berkunjung ke Bukittinggi karena penasaran dengan cita rasa Nasi Kapau selain itu pelanggan nasi kapau selama ini tergolong pelanggan yang royal sehingga bisa menyampikan review nya dengan senang hati.

Kata Kunci: Parawisata; Masakan Tradisional; Wisata Kuliner; Bauran Pemasaran.

\section{Pendahuluan}

Sumatera Barat adalah daerah yang telah dikaruniai berbagai kekuatan untuk aktivitas pariwisata dimulai dari wisata alam, budaya dan buatan. Secara umum wisatawan datang ke Sumatera Barat untuk melihat daerah-daerah objek wisata sekaligus juga tertarik pada masakan tradisionalnya, yang dikenal dengan Nasi Padang. Makanan Tradisional Sumatera Barat beragam rupanya bukan hanya nasi padang saja tetapi setiap daerah memiliki masakan khasnya sendiri. Dengan kekuatan daya tarik masakan khas daerah membuat posisi Sumatera Barat diuntungkan dengan mendapatkan fasilitas pendukung dalam kegiatan wisata sehingga menjadi daya tarik sendiri yang lebih sering dikenal dengan wisata kuliner.

Wisata kuliner bukan semata-mata keinginan untuk mencicipi nikmatnya makanan saja tetapi yang lebih penting adalah keunikan dan kenangan yang ditimbulkan setelah menikmati makanan tersebut. (Syarifuddin, M. Noor, \& Rohendi, 2017). Wisata kuliner merupakan salah satu jenis wisata yang dapat meningkatkan ekonomi warga lokal yang berperan dalam menciptakan lapangan pekerjaan, dan menciptakan kesejahteraan masyarakat. Hal ini terbukti semakin banyaknya tempat wisata yang terkenal dengan wisata kuliner seperti Kota Payakumbuh dengan pusat rendang (Ardy \& Yulihasri, 2020), Padang Pariaman dengan menonjolkan wisata kulinernya berupa Sala Lauak (Wahyuni, Baidar, \& Syarif, 2015) dan Kota Bukittinggi yang terkenal dengan wisata kuliner Nasi Kapau yang berada di pasar lereng Bukittinggi (Auliya, 2021).

Kota Bukittinggi terus mengembangkan wisatanya, hasil penelitian terdahulu yang dilakukan oleh Adrian (2018) mengembangkan wisata Kota Bukittinggi dengan pendekatan wisata kuliner seperti kuliner Nasi Kapau di Pasar Lereng Bukittinggi. Nasi Kapau merupakan nasi khas yang terdiri dari nasi, lauk pauk khas Kapau, dan gulai khas Kapau yang terdiri dari pilihan sayur nangka (cubadak), gulai tunjang (urat kaki kerbau/sapi), gulai babek (babat) atau perut kerbau (paruik kabau). Nasi Kapau dikemas dalam panci besar yang disusun-susun. Panci-panci terlalu jauh dari jangkauan tangan mereka sewaktu melayani pembeli, sehingga sendok gulai bertangkai panjang dari tempurung kelapa digunakan untuk menyendok gulai ke piring makan pembeli menjadi khas tersendiri.

Citarasa Nasi Kapau yang sangat khas dan proses pelayanan yang berbeda dari rumah makan minang lainnya menjadi nilai tambah untuk wisatawan yang ingin datang dan berkunjung ke Bukittinggi (Sulthon Auliya, 2021). Dengan segala persepsi yang ada di benak wisatawan untuk 
wisata kuliner Nasi Kapau akan menjadi peluang untuk Kota Bukittinggi fokus melakukan promosi pariwisata nya dengan menonjolkan wisata kuliner Nasi Kapau. Fungsi promosi secara umum dalam bauran pemasaran adalah untuk mencapai berbagai tujuan komunikasi dengan setiap wisatawan (Agusetyaningrum, Mawardi, \& Pangestuti, 2016).

Melakukan promosi wisata tidak bisa dilakukan dengan gegabah, hal ini dibutuhkan sebuah strategi sebelum penerapannya (Wijayanti, 2021). Hasil analisa awal peneliti sebelum melakukan penelitian lebih dalam dengan metode wawancara dengan wisatawan yang telah datang mencicipi Nasi Kapau bahwa potensi wisata kuliner Nasi Kapau dimulai dari promosi kekuatan promosi mulut ke mulut dan media sosial, dengan pola wisatawan yang sudah mencoba Nasi Kapau akan memberikan rekomendasi kepada kerabat atau kolega. Melihat peluang ini penulis tertarik untuk meneliti strategi promosi destinasi Bukittinggi melalui wisata kuliner nasi kapau dengan metode penelitian analisis SWOT sebab dengan metode ini menemukan nilai dari internal dan eksternal yang dimiliki oleh Nasi Kapau yang berada di Pasar Lereng Bukittinggi.

Penelitian sebelumnya oleh Auzan Tawadlu Akbar dan Edriana Pangestuti dengan judul Peran Kuliner Dalam Meningkatkan Citra Destinasi Pariwisata Taman Nasional Bromo Tengger Semeru, dengan hasil peran yang bersifat positif, dalam penelitiannya, hasilnya citra destinasi terbentuk dari wisatawan yang pernah mengunjunginya. Rasa dari makanan yang disajikan, penggunaan bahan baku yang masih segar, pemandangan alam yang indah, dan perizinan untuk membuka usaha jasa makanan dan minuman menjadi faktor pendukung . Dari penelitian tersebut menemukan faktor yang dapat menghambat peningkatan citra TNBTS melalui kuliner yang disajikan. Faktor-faktor penghambat tersebut ialah SDM belum berkualitas, penetapan harga, kesehatan dan kebersihan kuliner yang disediakan, proses memasak kuliner yang lama, dan penyediaan air yang terbatas (Akbar \& Pangestuti, 2017). Oleh sebab itu, berdasarkan pemaparan masalah yang ada penulis tertarik untuk menganalisa strategi promosi Kota Bukittinggi melalui wisata kuliner Nasi Kapau dengan rumusan masalah, apa saja peluang, kekuatan, kelemahan dan ancaman promosi wisata Bukittinggi melalui pendekatan wisata kuliner Nasi Kapau? dan bagaimana strategi yang cocok untuk promosi Kota Bukittinggi melalui pendekatan wisata kuliner Nasi Kapau? Dengan tujuan penelitian mengetahui sejauh mana peluang peningkatan promosi destinasi dengan wisata kuliner dan untuk mengetahui bagaimana strategi promosi yang bagus digunakan untuk promosi destinasi melalui bauran pemasaran.

\section{Literature Review}

\subsection{Makanan Tradisional sebagai Wisata Kuliner}

Makanan tradisional adalah makanan dan minuman yang biasa dikonsumsi oleh masyarakat tertentu yang memiliki cita rasa khas dan diterima oleh masyarakat tersebut. Dalam pembuatan makanan tradisional peranan budaya sangat penting, terutama keterampilan, kreativitas, sentuhan seni, tradisi dan selera. Makin tinggi budaya suatu komunitas, makin luas variasi bentuk makanan dan makin kompleks cara pembuatannya serta semakin rumit cara penyajiannya (Syarifuddin et al., 2017). Kompleksitas dan keunikan budaya tersebut dalam sektor pariwisata merupakan daya tarik yang sangat penting (Firdaus, 2018), termasuk kuliner. Dalam hal ini, Nasi Kapau adalah makanan tradisional khas daerah Kapau di Sumatera Barat dengan cita rasa yang khas dan proses pembuatannya yang disentuh dengan sentuhan tradisi.

Perkembangan tren pariwisata saat ini yaitu wisata kuliner dengan mengadopsi dari kekuatan makanan tradisional di setiap destinasi. Wolf juga menjelaskan bahwa culinary tourism is not prentious for exclusive. Its includes any unique and memorable gastronomic experience, not just restaurant rate four star or better and include both food and all type of beverages" (Saeroji \& Wijaya, 2017). Dalam pernyataan ini dapat tergambarkan bahwa wisata kuliner tidak menuntut sebuah kemewahan tetapi lebih kepada seni kuliner dengan pengalaman yang menjadi daya tariknya. 
Wisata kuliner adalah suatu aktivitas wisatawan untuk mencari makanan dan minuman yang unik dan mengesankan sehingga bukan semata-mata keinginan untuk mencicipi nikmatnya makanan, tetapi yang lebih penting adalah keunikan dan kenangan yang ditimbulkan setelah menikmati makanan tersebut (Agusetyaningrum et al., 2016). Wisata kuliner membuat makanan seperti subjek dan media, serta menjadi tujuan wisata bagi wisatawan. Wisata kuliner diperlukan kerjasama semua panca indra seperti lidah, hidung, indra peraba, serta mata. Dari penjelasan tersebut dapat dikatakan bahwa seni kuliner merupakan suatu seni yang mempelajari tentang makanan dan minuman serta berbagai hal yang berhubungan dengan makanan dan minuman tersebut, mulai dari persiapan, pengolahan, penyajian, dan penyimpanannya (Syarifuddin et al., 2017).

\subsection{Bauran Pemasaran}

Menurut Kotler dan Amstrong, 2006 dalam (Rustandi Kartawinata, Wardhana, \& Kartawinata, 2015), "Marketing mix is the set of tactial marketing tools that the firm blend to produce the response it want in the target market". Buaran pemasaran ini sebagai alat untuk mencapai target maket antara lain:

\subsubsection{Produk (Product)}

Produk adalah keseluruhan konsep objek atau proses yang memberikan sejumlah nilai manfaat kepada konsumen. Kualitas produk juga sebuah kegiatan menghadirkan barang-barang yang sesuai dengan bisnis yang dijalani oleh perusahaan dengan bermutu atau berkualitas baik ( disini tentu kualitas produk adalah bahan-bahan yang masih baru dengan standar kualitas. Kebijakan produk yang perlu diperhatikan adalah mengenai model, merk, label dan kemasan (Rachmawati, 2011).

\subsubsection{Lokasi (Place)}

Lokasi merupakan faktor yang penting dalam mencapai keberhasilan sebuah restoran. Keberhasilan tersebut ditopang oleh faktor penentu, yaitu good visibility, easy access, convenience, curb side appeal, parking. Oleh karena itu, pemilihan lokasi dalam membangun dan mengembangkan restoran sangat menentukan tingkat keterkunjungan sebuah restoran oleh konsumen (Rachmawati, 2011).

\subsubsection{Promosi (Promotion)}

Promosi adalah aktivitas yang dilakukan restoran untuk mencari konsumen, bukan hanya untuk sekali datang, tetapi juga konsumen yang akan melakukan pembelian berulang (pelanggan). Tujuan dari promosi adalah meningkatkan awareness meningkatkan persepsi konsumen, menarik pembeli pertama, mencapai persentase yang lebih tinggi untuk konsumen yang berulang, menciptakan loyalitas merek, meningkatkan average check, meningkatkan penjualan pada makanan tertentu atau waktu-waktu khusus, dan mengenalkan menu baru. Cara promosi yang dapat dilakukan antara lain dengan promosi mounth by mounth, mengikuti event-event tertentu, mengadakan diskon khusus pada saat tertentu, memberi member card pada pelanggan. Dapat juga dilakukan melalui promosi seperti reklame, sisipan pada koran dan media massa atau menggunakan spanduk (Agusetyaningrum et al., 2016).

\subsubsection{Harga (Price)}

Harga adalah satuan moneter atau ukuran lainnya termasuk barang dan jasa lainnya yang ditukarkan agar memperoleh hak kepimilikan atau pengguna suatu barang dan jasa. Harga juga merupakan pertimbangan yang penting dalam memilih restoran. Faktor-faktor yang mempengaruhi harga yang diterapkan dalam sebuah restoran, adalah: hubungan antara permintaan dan penawaran, penurunan loyalitas konsumen, sales mix, harga-harga dalam persaingan, biaya overhead, aspek psikologis, kebutuhan untuk meraih laba. Cara menentukan 
harga yang tepat adalah dengan melihat harga jual pesaing sejenis, tentunya dengan kualitas dan porsi makanan yang kira-kira sama (Rachmawati, 2011).

\subsubsection{Orang (People)}

Faktor penting dalam sumber daya manusia adalah attitude dan motivasi dari karyawan dalam industri jasa. Attitude dapat diaplikasikan dalam berbagai bentuk, seperti penampilan karyawan, suara dalam bicara, body language, ekspresi wajah, dan tutur kata (Akbar \& Pangestuti, 2017). Sedangkan motivasi akan menentukan sejauh apa karyawan ingin atau menyukai pekerjaan yang akan dilakukan.

\subsubsection{Proses (Process)}

Proses di sini mencakup bagaimana cara perusahaan melayani permintaan tiap konsumennya, mulai dari konsumen memesan (order) hingga akhirnya mereka mendapatkan apa yang mereka inginkan. Beberapa perusahaan tertentu biasanya memiliki cara yang unik atau khusus dalam melayani konsumennya.

\subsubsection{Tampilan Fisik (Physical Evidence)}

Tampilan fisik tempat usaha akan menjelaskan bagaimana penataan bangunan dari suatu perusahaan. (Mashadi, 2019) Apakah perusahaan menggunakan interior yang unik, lightning system yang menarik, desain ruangan yang menarik perhatian, dan lain sebagainya. Bangunan harus dapat menciptakan suasana yang menyenangkan, sehingga memberikan pengalaman kepada pengunjung dan dapat memberikan nilai tambah.

\section{Metode Penelitian}

Penelitian berlokasi di Kota Bukittinggi, tepatnya di Pasar Lereng Bukittinggi dan menjawab rumusan masalah, penelitian ini menggunakan pendekatan mixed methods yang sering dikenal dengan penelitian campuran (Dhanita \& Hidayat, 2015). Penelitian kombinasi dengan kualitatif dan kuantitatif. Kualitatif dengan pengumpulan data observasi, wawancara kepada seluruh pedagang Nasi Kapau di Pasar Lereng Bukittinggi dan kuantitatif dengan penyebaran angket kepada wisatawan yang datang berkunjung dan membeli Nasi Kapau di Pasar Lereng Bukittinggi pada waktu liburan atau waktu dengan tingkat kunjungan yang tinggi pada daerah Bukitiinggi adalah bulan Desember 2020 dan tahun 2021 pada bulan Januari, Juni dan Juli dengan teknik penentuan sample untuk ukuran populasi tidak terhingga.

Jenis penelitian ini dengan penelitian eksploratif, Suharsimi Arikunto (Agusetyaningrum et al., 2016) mengemukakan bahwa penelitian eksploratif merupakan penelitian dengan menggali pengetahuan dan suatu permasalahan dengan menggambarkan secara rinci kekuatan, kelemahan, peluang dan ancaman sehingga dapat memberikan penjelasan segala gejala yang terjadi dengan mendalam dengan menggunakan teknik analisis data analisa SWOT. Menurut Freddy Rangkuti dalam (Syaifulla, 2020) merupakan analisa terhadap lingkungan internal maupun eksternal, lingkungan eksternal meliputi peluang dan ancaman yang akan mempengaruhi pemanfaatan potensi kuliner khas Bukittinggi dalam meningkatkan promosi pariwisata Kota Bukittinggi kemudian memasukkan data ke dalam matrix IFAS dan EFAS dan pemberian skor untuk rating faktor dengan tabulasi.

\section{Hasil dan Pembahasan}

\subsection{Analisis Bauran Pemasaran Nasi Kapau Bukittinggi}

\subsubsection{Produk (Produk dari Kuliner Nasi Kapau)}

Nasi Kapau menyediakan menu kurang lebihnya 9 macam, diantaranya adalah Tunjang, Usus atau Tambusu, Babat, Gulai Ayam, Goreng Ayam Lado Ijau, Dendeng Bumbu, Dendeng 
Lambok, Dendeng Kariang, Randang Ayam. Perbedaan produk Nasi Kapau dengan restoran minang lainnya yaitu pada Nasi Kapau tidak menyediakan Rendang Daging, karna mereka menyediakan hanya Rendang Ayam. Selain itu, Nasi Kapau juga tidak menyediakan Ikat Laut. Kebijakan produk dari Nasi Kapau yang menjadi perhatian adalah pada Nasi Kapau bukan hanya nasi, lauk saja tetapi samiak dalam istilah minang yang dapat diartikan potongan-potongan lauk lainnya dengan ukuran kecil seperti dendeng kering potongan kecil atau rendang kentang dengan potongan yang kecil-kecil. Selain itu, produk dalam kuliner Nasi Kapau adalah sebuah rasa. Rasa yang kaya akan bumbu.

\subsubsection{Price (Harga Kuliner Nasi Kapau)}

Harga yang ditetapkan terhadap Kuliner Nasi Kapau sudah sesuai dan di setiap penjual Nasi Kapau lainnya, varian harganya hanya terletak pada pengunjung yang membeli Nasi Kapau dan memakannya di tempat orang yang jualan Nasi Kapau tersebut, maka harga yang di tetapkan sebesar Rp. 28.000, dan jika pengunjung membeli Nasi Kapau ini dengan meminta untuk dibungkus maka harganya sebesar Rp. 30.000. Jika pengunjung hanya memesan lauknya saja tidak dengan nasi, maka harga yang di berikan sebesar Rp. 20.000.

Penetapan harga sudah tepat dengan kualitas dan porsi makanan yang disajikan. Bila dibandingkan dengan restoran minang secara umum, memang Nasi Kapau masuk dalam katagori harga yang cukup mahal, namun dengan harga tersebut sesuai dengan yang didapat dimana porsi untuk makan langsung dengan tambahan lauk yang sesuai dengan harga dan untuk bungkus dengan porsi yang lebih banyak dari makan langsung tentu akan terjadi pembedaan harga dan untuk pesaing harga Nasi Kapau di Pasar Lereng Bukittinggi sudah ditetapkan sama seluruhnya. Dengan demikian, promosi harga ini tidak menjadi halangan untuk mencicipi wisata kuliner Nasi Kapau di Pasar Lereng Bukittinggi

\subsubsection{Place (Lokasi Nasi Kapau)}

Usaha Nasi Kapau adalah usaha turun temurun, jadi penjual Nasi Kapau kini yang berjualan sekarang tentunya meneruskan tempat usaha yang sudah dijalankan oleh terdahulu terutama untuk lokasi. Bila dianalisis dari good visibility lokasi di Pasar Lereng sudah sesuai dengan peletakan yang bersih sehingga seluruh menu di Nasi Kapau terpajang atau terdisplay sebagai mana mestinya kemudian untuk akses sudah mudah diakses/easy access dengan lokasi yang nyaman untuk makan dengan terbuka dan antara kedai nasi kalau dihalangi oleh kain-kain putih sehingga sudah menggambarkan convenience dengan baik dan curb side appeal tradisional yang tergambarkan dengan baik dilokasi tersebut serta dilengkapi dengan area parking yang terpusat dimana tempat jualan Nasi Kapau ini terletak di pasar wisata dan terletak tidak jauh dari pusat objek wisata Bukittinggi, yaitu Jam Gadang.

\subsubsection{Promosi}

Pedagang Nasi Kapau di Pasar Lereng Bukittinggi tidak melakukan promosi secara terpadu dan terstruktur. Kegiatan promosi yang pernah dilakukan oleh pedagang Nasi Kapau ini dengan melayani dengan baik seorang Youtuber yang berkunjung untuk menikmati masakan Nasi Kapau sehingga ini sekaligus mempromosikan kelezatan dari Nasi Kapau ini sendiri. Selain itu juga ada beberapa artis yang berkunjung dalam acara TV swasta tentang kuliner dan meliput sedang menikmati Nasi Kapau sekaligus artis tersebut memposting kegiatannya saat mengunjungi Nasi Kapau pada media sosial.

Penjual Nasi Kapau sendiri pun tidak terlalu melakukan strategi promosi, tetapi promosi yang dilakukan adalah melakukan konsistensi rasa yang terus sama sehingga wisatawan yang berkunjung akan terus merekomendasikan dan terjadi promosi dari mulut ke mulut dengan 
harapan wisatawan ini akan datang kembali dan loyal untuk makan Nasi Kapau ketika kembali ke Bukittinggi.

\subsubsection{People (Orang)}

Sumber daya manusia dalam usaha Nasi Kapau terdiri dari tukang masak dan tukang menyanduak. Tukang masak lebih fokus kepada bagian dapur dan tukang sanduak sekaligus sebagai pelayan. Untuk menyanduak memiliki teknik yang khusus maka dilakukan oleh sumber daya manusia yang berkompeten dan berpengalaman dalam menyanduak Nasi Kapau. Nasi Kapau sebagai usaha yang bergerak dalam jasa untuk sumber daya manusia sangat dibutuhkan attitude dalam bekerja. Dalam dapur attitude untuk bekerjasama dan saling percaya dan untuk pelayanan yaitu melayani pengunjung dengan sopan, santun dan ramah serta didukung oleh penampilan yang rapi, bersih dan ciri khas dari tukang sanduak adalah identik dengan ibu-ibu.

\subsubsection{Psycal Evidence (Tampilan Fisik)}

Tampilan fisik tempat usaha Nasi Kapau seperti bilik dimana setiap pedagang dipisahkan oleh hordeng putih dan proses tempat makan yang persegi dimana sentral tampilan tersebut adalah menu makanan yang disusun untuk dihidangkan oleh Nasi Kapau. Tampilan fisik dari tempat makan Nasi Kapau sedikit terbuka dan agak sempit seperti kubik tetapi hal tersebut telah menjadi keunikan tersendiri. Dalam penampilan fisik hidangan atau platting yang digunakan nasi kapau ini sederhana dimana adanya susunan piring-piring namun dalam susunan tersebut tidak perlu adanya susunan yang khusus karena platting yang digunakan adalah tradisi yang sudah turun menurun.

\subsubsection{Process (Proses)}

Proses dalam pelayanan permintaan tiap konsumen dalam usaha Nasi Kapau sangat unik, mulai dari konsumen memesan (order) dengan langsung menunjuk lauk yang diinginkan dimana lauk tersebut disusun bertingkat-tingkat oleh penjual Nasi Kapau hingga terlihat unik dan bagus susunannya. Dengan letak masakan yang bertingkat-tingkat ini penjual Nasi Kapau duduk agak tinggi agar kelihatan oleh pembeli dan agar bisa menjangkau masakan yang dipesan oleh pengunjung dengan cepat. Penjual Nasi Kapau mengambil lauk yang ada di masakan Nasi Kapau ini menggunakan sanduak (sendok) yang panjang. Hal ini merupakan ciri dari semua penjual Nasi Kapau, dan supaya lebih mudah mengambil masakan yang letaknya pada tingkat bawah. Adapun nuansa yang didapatkan adalah makan dengan makanan yang hangat dan bebas memilih lauk dan kuah yang diinginkan.

\subsection{Strategi Promosi Nasi Kapau dalam Analisis SWOT}

Setelah dilakukan analisis, kemudian penulis menyebarkan kuesioner kepada wisatawan yang berkunjung dan makan Nasi Kapau dengan menentukan kekuatan, kelemahan, peluang dan ancaman dari Nasi Kapau sebagai media promosi destinasi dengan pembagian faktor strategis sebagai berikut;

Table 1. Faktor Internal

\begin{tabular}{ll}
\hline & \multicolumn{1}{c}{ Internal - faktor strategis } \\
\hline Kekuatan & Variasi makanan yang sangat identik dengan minang \\
& Tempat yang dekat dengan objek wisata \\
& Proses penyajian (menyanduak) yang unik \\
Kelemahan & Pelayan kurang ramah \\
& Harga mahal \\
& Tampilan masakan yang kurang menarik \\
& Source: Data Peneliti (2021)
\end{tabular}

Source: Data Peneliti (2021) 
Table 2. Faktor Eksternal

\begin{tabular}{ll}
\hline & \multicolumn{1}{c}{ Eksternal - faktor strategis } \\
\hline Peluang & Rasa masakan yang memiliki ciri khas \\
& Promosi yang kuat dari kepercayaan mulut ke mulut \\
Tantangan & Pilihan makanan yang kurang baik untuk kesehatan \\
& Lokasi terlalu terbuka sehingga kurang memberikan rasa aman \\
\hline & \multicolumn{1}{c}{ Source: Data Peneliti (2021) }
\end{tabular}

Berdasarkan faktor-faktor strategis di atas, penulis melakukan analisi SWOT. Hasil analisis dibagi menjadi faktor internal dan faktor eksternal. Adapun hasil analisis faktor internal adalah sebagai berikut:

Table 3. Analisis SWOT Faktor Internal

\begin{tabular}{llrrr}
\hline & \multicolumn{1}{c}{ Internal - Faktor Strategis } & Bobot & Rating & Skor \\
\hline Kekuatan & Variasi makanan yang sangat identik dengan minang & 0.23 & 5.00 & 1.14 \\
& Tempat yang dekat dengan objek wisata & 0.14 & 3.25 & 0.44 \\
\multirow{3}{*}{ Kelemahan } & Proses penyajian (menyanduak) yang unik & 0.16 & 4.50 & 0.72 \\
& Pelayan kurang ramah & 0.14 & 1.50 & 0.20 \\
& Harga mahal & 0.18 & 2.75 & 0.50 \\
& Tampilan masakan yang kurang menarik & 0.16 & 1.00 & 0.16 \\
& TOTAL Source: Peneliti (2021) & & & 3.16 \\
\hline
\end{tabular}

Secara internal Nasi Kapau memiliki peluang yang besar untuk dijadikan media promosi destinasi Kota Bukittinggi dengan kekuatan produk makanan yang memiliki variasi yang banyak dan branding yang terkenal sebagai masakan minang. Selain produk masakan Nasi Kapau yang banyak pilihan tersebut, ditambah kekuatan proses penyajian dengan menyanduak (cara pengambilan) yang unik, menambah kesan yang indah dalam masakan Nasi Kapau. Dengan memperhatikan kelemahan harga yang mahal namun dengan respon yang baik yaitu harga mahal sepadan dengan yang didapatkan wisatawan, yaitu ukuran atau porsi yang besar. Kelemahan tampilan masakan yang kurang menarik mulai dapat dilakukan pembenahan agar semakin menarik perhatian wisatawan untuk mencicipi masakan Nasi Kapau.

Adapun Analisis SWOT eksternal sebagai berikut:

Table 3. Analisis SWOT Eksternal Faktor

\begin{tabular}{llrrr}
\hline & Eksternal - Faktor strategis & Bobot & Rating & Skor \\
\hline Peluang & Rasa makanan yang memiliki ciri khas & 0.3 & 4 & 1.2 \\
& Promosi kepercayaan yang kuat dari mulut ke mulut & 0.2 & 1.5 & 0.3 \\
\multirow{3}{*}{ Tantangan } & Pilihan menu makanan yang kurang baik untuk kesehatan & 0.3 & 2 & 0.6 \\
& Lokasi terlalu terbuka sehingga kurang aman & 0.2 & 1.5 & 0.3 \\
\hline \multicolumn{2}{c}{ Total Sumber: Data Peneliti (2021) } & 1 & & 2.4 \\
\hline
\end{tabular}

Secara eksternal Nasi Kapau memiliki peluang dengan cita rasa yang sudah khas yang memang identik dengan Nasi Kapau yaitu kuah gulai yang beraneka ragam dalam 1 piring dan ancaman nya dengan begitu banyak kuah gulai dalam 1 piring mengancam kesehatan sehingga tingkat kolerterol dan penyakit lain menjadikan poin dalam ancaman.

Dengan memperhatikan kelemahan harga yang mahal namun dengan respon yang baik yaitu harga mahal sepadan dengan yang didapatkan wisatawan yaitu ukuran atau porsi yang besar. Untuk kelemahan tampilan masakan yang kurang menarik mulai dapat dilakukan pembenahan tanpa harus menghilangkan nuansa nyamannya dan identic dengan khas Nasi Kapau. 


\section{Diskusi dan Kesimpulan}

Strategi promosi Kota Bukittinggi melalui pendekatan wisata kuliner Nasi Kapau bila dianalisis dengan metode analisis SWOT berada pada kuadran I yang berarti strategi yang cocok digunakan adalah strategi yang agresif. Hasil analisis tersebut dapat dijelaskan melalui gambar dibawah ini.

Gambar 1. Matrix SWOT

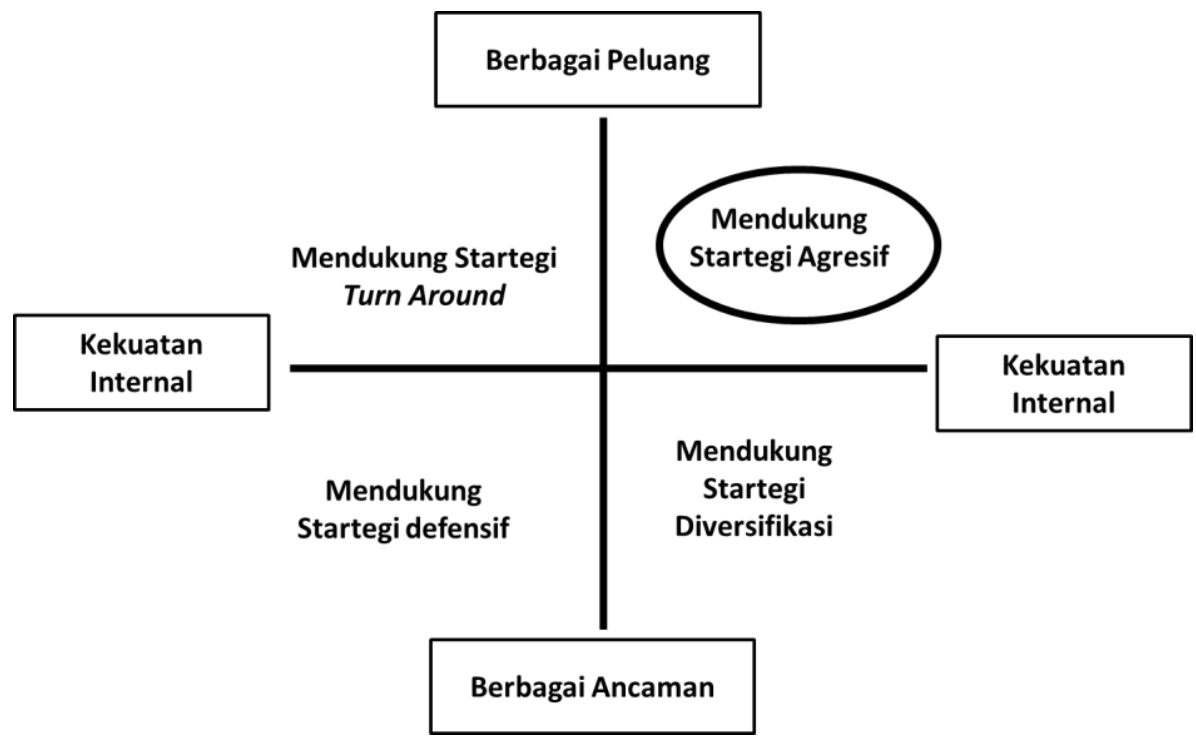

Sumber: Data Peneliti, 2021

Poin yang tinggi berada pada kekuatan pilihan menu yang bervariasi dan pilihan menu tersebut sangat identik dengan ciri khas masakan minang harus ditonjolkan saat menjadikan nasi kapau untuk dipromosikan pada wisata kuliner Kota Bukittinggi. dalam melakukan promosi wisata kuliner. Selain nilai pilihan menu dan ciri khas nasi Kapau yang sudah melekat dengan masakan minang juga ditemukan sebuah peluang untuk lebih gencar melakukan promosi yang mulut ke mulut. Hal ini juga dapat dilakukan dengan perkembangan teknologi yaitu membuat Nasi Kapau menjadi viral dan menjadi bahan omongan banyak orang memunculkan rasa penasaran wisatawan untuk datang ke Bukittinggi dan mencicipi Nasi Kapau.

Dengan melakukan promosi dengan agresif secara inbone dan outbone tentu akan menjadi peluang yang sangat baik untuk menarik hati wisatawan berkunjung ke Bukittinggi dengan nilai unik yaitu Nasi Kapau. Kemudian, pelakukan agresif juga bisa membuat sebuah project untuk menyatukan seluruh komentar-komentar baik tentang Nasi Kapau sebab disini konsumen Nasi Kapau adalah konsumen yang royal untuk menceritkan kenikmatan nasi kapau.

Dalam melakukan promosi secara agresif tentu juga harus diimbangi dengan persiapan pelayanan yang maksmimal untuk seluruh pedagang, hal ini bisa dilakukan dengan adakan workshop atau penyuluhan untuk sadar wisata bagi penjual Nasi Kapau sebab ketika sudah menjadikan Nasi Kapau sebagai salah satu icon wisata kuliner Bukittinggi pedangan bukan hanya sebbagai penjual saja tetapi juga memberikan jasanya berupa pelayanan yang prima sehingga wisatawan memiliki nilai puas akan pelayanan dan rasa.

Selanjutnya, strategi yang digunakan dengan melakukan inovasi pada Nasi Kapau yang lebih sehat atau mempertimbangkan nilai kesehatan seperti memperkecil kemungkinan kolesterol setelah memakan Nasi Kapau dan dilakukan improvisasi lokasi yang tidak terlalu terbuka atau membuat setting atau tata letak yang lebih privasi untuk terwujudnya rasa aman saat mencicipi Nasi Kapau dan meningkatkan loyalitas costumer sehingga promosi dari mulut ke mulut terus berlanjut atau tidak terputus dengan nilai-nilai positif mengenai kuliner Nasi Kapau. 
Melalui tercukupinya poin-poin dari bauran pemasaran dan dianalisis dengan SWOT maka Nasi Kapau berada dalam posisi yang menguntungkan untuk Kota Bukittinggi sehingga pilihan untuk melakukan promosi Kota Bukittinggi melalui daya tarik wisata kuliner Nasi Kapau di Pasar Lereng Bukittinggi adalah pilihan yang tepat dan pelaksanaan promosi ini perlu dilakukan dengan intens dan gencar yang bersifat agresif.

\section{Konflik Kepentingan}

Penulis dengan ini menyatakan bahwa tidak adanya konflik kepentingan dalam penulisan artikel ini.

\section{Daftar Pustaka}

Adrian, T., \& Sadad, A. (2018). Pengembangan Pariwisata kota Bukittinggi dalam meningkatkan Pendapatan Asli Daerah. JOM FISIP, 5(1), 1-13.

Agusetyaningrum, V., Mawardi, M., \& Pangestuti, E. (2016). Strategi Pengembangan Usaha Kecil Dan Menengah (UKM) Untuk Meningkatkan Citra Kota Malang Sebagai Destinasi Wisata Kuliner (Studi Pada UKM Berbasis Kuliner Kota Malang). Jurnal Administrasi Bisnis S1 Universitas Brawijaya, 38(2), $105-111$.

Akbar, A., \& Pangestuti, E. (2017). Peran Kuliner Dalam Meningkatkan Citra .Destinasi.Pariwisata Taman Nasional Bromo Tengger Semeru. Jurnal Administrasi Bisnis S1 Universitas Brawijaya, 50(1), 153-159.

Ardy, N., \& Yulihasri, Y. (2020). Strategi Pengembangan Atraksi Pengolahan Rendang (Marandang) Sebagai Daya Tarik Wisata Gastronomi Di Kampung Rendang Kota Payakumbuh. Jurnal Ekonomi, 23(2), 134-154. https://doi.org/10.47896/je.v23i2.216

Auliya, S. (2021). Persepsi Wisatawan Domestik Terhadap Wisata Kuliner Nasi Kapau di Los Lambuang Bukittinggi. Universitas Gadjah Mada.

Dhanita, L., \& Hidayat, A. (2015). Gambaran Adversity Quotient pada Wirausahawan Melayu di Bidang Kuliner. An-Nafs, 09(03), 1-14.

Firdaus, F. (2018). Potency of Integrated Cultural Tourism Development at Maninjau Lake Area, West Sumatera. Mimbar: Jurnal Sosial Dan Pembangunan, 34(1), 72-82. https://doi.org/10.29313/mimbar.v34i1.3113.72-82

Mashadi, A. Y. A. P. (2019). Tinjauan Permenpar No. 28 - 2015 Usaha Penjualan Makanan Pada Skala Mikro Kecil Surya Kencana Bogor. Jurnal IKRA-ITH Ekonomika, 2(3), 148-156.

Rachmawati, R. (2011). Peranan Bauran Pemasaran (Marketing Mix) terhadap Peningkatan Penjualan (Sebuah Kajian terhadap Bisnis Restoran. Jurnal Kompetensi Teknik, 2(2), 143-150.

Rustandi Kartawinata, B., Wardhana, A., \& Kartawinata, B. R. (2015). Marketing Strategies and Their Impact on Marketing Performance of Indonesian Ship Classification Society. Article in International Journal of Science and Research, 4(2), 69-74.

Saeroji, A., \& Wijaya, D. A. (2017). Pemetaan Wisata Kuliner Khas Kota Surakarta. Jurnal Pariwisata Terapan, 1(2), 13. https://doi.org/10.22146/jpt.24968

Syaifullah, I. P. (2020). Upaya Pemasaran Pupuk Organik Dan Racun Tanaman Berbasis Media Sosial. Universitas Bina Darma.

Syarifuddin, D., M. Noor, C., \& Rohendi, A. (2017). Memaknai Kuliner Lokal Sebagai Daya Tarik Wisaya. Abdimas, 1(1), 4-8.

Wahyuni, H., Baidar, B., \& Syarif, W. (2015). Standarisasi Resep Sala Lauak Di Kanagarian Ulakan Kabupaten Padang Pariaman. Journal of Home Economics and Tourism, 9(2).

Wijayanti, A. (2021). Efektifitas Instagram dalam Meningkatkan Minat Kunjungan Wisatawan di Daerah Istimewa Yogyakarta. Indonesian Journal of Tourism and Leisure, 02(1), 26-39. https://doi.org/10.36256/ijtl.v2i1.138 